\title{
In vivo Toxicity and Antitumor Activity of Newly Green Synthesized Reduced Graphene Oxide / Silver Nanocomposites
}

Mohamed M. El-Zahed ( $\square$ mohamed.marzouq91@du.edu.eg )

Damietta University https://orcid.org/0000-0003-2694-3720

Zakaria Awad Baka

Damietta University

Mohamed Ismail Abou-Dobara

Damietta University

Ahmed Kassem El-Sayed

Damietta University

Magy Mohamed Aboser

Damietta University

Ayman Hyder

Damietta University

Research Article

Keywords: reduced graphene oxide, silver nanoparticles, in vivo toxicity, nanocomposites, antitumor, Ehrlich ascites carcinoma

Posted Date: March 26th, 2021

DOI: https://doi.org/10.21203/rs.3.rs-353063/v1

License: (c) (1) This work is licensed under a Creative Commons Attribution 4.0 International License. Read Full License 


\begin{abstract}
A novel biosynthesis of dual reduced graphene oxide/silver nanocomposites (rGO/AgNC) using the crude metabolite of Escherichia coli D8 (MF06257) strain and sunlight is introduced in this work. Physicochemical analysis of these $\mathrm{rGO} / \mathrm{AgNC}$ revealed that they are sheet-like structures having spherically shaped AgNPs with an average particle size of 8 to $17 \mathrm{~nm}$, and their absorption peak ranged from 350 to $450 \mathrm{~nm}$. The biosynthesized rGO/AgNC were characterized by UV-Vis and FT-IR spectra, X-ray diffraction and transmission electron microscopy. After the injection of these nanocomposites to mice, their uptake by the kidney and liver has been proven by the ultrastructural observation and estimation of the hepatic and renal silver content. These nanocomposites caused a moderate toxicity for both organs. Changes in the liver and kidney functions and histopathological effects had been observed. The rGO/AgNC revealed a remarkable antitumor effect. They showed a dose-dependent cytotoxic effect on Ehrlich ascites carcinoma (EAC) cells in vitro. Treatment of mice bearing EAC tumors intraperitoneally with $10 \mathrm{mg} / \mathrm{kg}$ rGO/AgNC showed an antiproliferative effect on EAC cells, reduced ascites volume, and maintained mice survival. The results indicate that this green synergy of silver nanoparticles with reduced-graphene oxide may have a promising potential in cancer therapy.
\end{abstract}

\title{
Introduction
}

Graphene oxide (GO) is one of the most common carbon compounds that could be synthesized throughout the oxidizing of graphite powder. Reduced graphene oxide ( $\mathrm{rGO}$ ) compounds have been reported as antimicrobial agents (Anand et al., 2019), enhancing materials for the wound healing (Ma et al., 2019), and anticancer agents (Dhanavel et al., 2020). These activities of the rGO were referred to the presence of the functionalized groups (carbonyl $(C=0)$, carboxyl (C-OOH), hydroxyl (C-OH), epoxy (C-O-C)) on its surface and edges (Rasoulzadehzali \& Namazi, 2018). Moreover, it is thought that the rGO has less oxygen related functional group and therefore it might be good for many medical applications (Morimoto et al., 2016). Also, silver nanoparticles (AgNPs) have been used as broad-spectrum antimicrobial agents (Nasr et al., 2020) in addition to their antiangiogenesis properties (Gomathi et al., 2020). Soica et al. (2018) reported that AgNPs enhanced the anticancer activities against MCF-7 (human breast cancer) cell lines in addition to their apoptosis and the antiangiogenesis action against Ehrlich ascites carcinoma (EAC) solid tumor was recorded by El-Sonbaty (2013) and Mukherjee et al. (2014).

In past few years, scientists have given much interest and attention for the synthesis of polymer-based nanocomposites (PNC) due to their inherent advantages of biological activities comparing with the nanometallic particles or the individual state of polymers (Idumah et al., 2019). Among PNC, reduced graphene oxide/silver nanocomposites ( $\mathrm{rGO} / \mathrm{AgNC}$ ) exhibit potent anticancer activities moreover their antimicrobial action (Pooresmaeil \& Namazi, 2019; Jose et al., 2020). Also, rGO/AgNC have been used in various applications including biomedical applications as wound dressing, anticancer activity and as drug delivery system (Zaidi, 2019), and industrial applications as water treatment, food packaging, cosmetics, and biosensors (Ceran et al., 2020).

Green synthesis of PNC using microorganisms are considered as a better way than chemical and physical metahods due to their advantageous characteristics such as safety, easy and rapid processing, stability, low cost, and flexibility (Sabayan et al., 2020). Recent studies have revealed that the crude metabolites of bacteria such as Escherichia and Streptomyces sp. act as strong bioreductant agents and could be used as microbial nano factories (Yusof et al., 2020, Elsharawy et al., 2020).

The in vivo behavior and effect, and the biological activity of these rGO/AgNC in cancer cells have not been explored. The present study provides a green approach for the synthesis of rGO/AgNC using crude metabolite of E. coli D8 (AC: MF062579), their characterization, in vivo effect, and anticancer activity in mice. The presented work is, to our knowledge, a first study for the in vitro and in vivo uptake and antitumor activity of rGO/AgNC.

\section{Materials And Methods Preparation of E. coli D8 bacterial metabolite}

Escherichia coli D8 (AC: MF062579) used in the biosynthesis of AgNPs was obtained from our culture collection. The bacterial strain was regularly subcultured on nutrient agar plates $\left(37^{\circ} \mathrm{C}, 24 \mathrm{~h}\right.$.). The developed well separated colonies of bacteria were picked up and grown on nutrient broth medium $\left(37^{\circ} \mathrm{C}, 150 \mathrm{rpm}, 48 \mathrm{~h}\right) .200 \mu \mathrm{L}$ culture of $E$. coli D8 ( $0.5 \mathrm{McF}$ arland standard ( $\left.\left.1-2 \times 10^{8} \mathrm{CFU} / \mathrm{ml}\right)\right)$ was inoculated into $250 \mathrm{ml}$ Erlenmeyer flasks containing 50 $\mathrm{ml}$ of nutrient broth medium $\left(37^{\circ} \mathrm{C}, 150 \mathrm{rpm}, 48 \mathrm{~h}\right)$. After incubation, the bacterial metabolites were collected by centrifugation at $5000 \mathrm{rpm}$ for $15 \mathrm{minutes}$.

\section{Synthesis of reduced graphene oxide/silver nanocomposites}

The synthesis protocol of $\mathrm{rGO} / \mathrm{AgNC}$ included the oxidation of graphite powder using strong oxidizing agents followed by reduction of GO and decoration with AgNPs. Here, the GO was prepared by oxidizing the pristine graphite powder (Loba Chemie Pvt. Ltd., India) according to Hummers \& Offeman (1958) method. In brief, $2 \mathrm{~g}$ graphite powder was added into $50 \mathrm{ml}$ of concentrated sulfuric acid in an ice-water bath and then stirred for $2 \mathrm{~h}$ at $35^{\circ} \mathrm{C}$. The mixture was diluted with $350 \mathrm{ml}$ distilled water. Twenty $\mathrm{ml}$ of $30 \%$ hydrogen peroxide was added to the reaction mixture drop by drop. The resulting GO was washed out with $5 \%$ $\mathrm{HCl}$ solution and then with distilled water to achieve the $\mathrm{pH}$ of 7 . The solution was centrifuged at $10,000 \mathrm{rpm}$ for 15 minutes and dried in an oven at $60^{\circ} \mathrm{C}$ for $24 \mathrm{~h}$.

For the synthesis of $\mathrm{rGO} / \mathrm{AgNC}, 0.15 \mathrm{~g}$ of the synthesized GO particles were dispersed in $50 \mathrm{~mL}$ distilled water and submitted to $2 \mathrm{~h}$ ultrasonication at $25^{\circ} \mathrm{C}$ (ultrasonic bath, $28 \mathrm{kHz}$ Delta-sonic $920 \mathrm{~N}^{\circ}$ 484, Meaux, France). Then, $0.5 \mathrm{~g}$ of silver nitrate $\left(\mathrm{AgNO}_{3}\right)$ (Panreac Quimica S.L.U, Barcelona, Spain) was added to the aqueous solution gradually and shacked well till solvation. In one step, twenty $\mathrm{mL}$ E. coli D8 crude metabolite were added as media for dual reducing procedure for both $\mathrm{AgNO}_{3}$ and $\mathrm{GO}$ in the presence of sunlight. At first, the color was turned into dark brown indicated to the formation of AgNPs then turned into dark violet-brown color indicated to the binding of AgNPs to the formed rGO. After $15 \mathrm{~min}$, the rGO/AgNC powder was obtained by centrifugation at 10,000 rpm for 15 minutes several times and then dried in an oven at $60^{\circ} \mathrm{C}$ for $24 \mathrm{~h}$. 


\section{Characterization of the synthesized graphene oxide/silver nanocomposites}

Ultraviolet-visible (UV-vis) spectral analysis and Fourier transform infrared spectroscopy (FT-IR) of the formed GO and rGO/AgNC were done using UV/VIS/NIR Spectrophotometer (V-630, Japan) and FT/IR-4100typeA respectively. The X-ray diffraction (XRD) patterns of the GO and rGO/AgNC were recorded at $2 \theta$ values between $10^{\circ}$ and $80^{\circ}$ using a Cu X-ray tube at $40 \mathrm{kV}$ and $30 \mathrm{~mA}$ with the X-ray diffractometer (model LabX XRD-6000, Shimadzu, Japan). Transmission electron microscopic analysis (TEM) was done using JEOL JEM-2100, Japan, as described before (Eldeeb et al., 2018).

\section{Ehrlich Ascites Carcinoma cells}

Transportable tumor (EAC) initial inoculum was provided by the Zoology department, Mansoura University, Egypt, in ascitic form and maintained by serial biweekly transplantations in our laboratories through intraperitoneal (i.p.) injections of $3 \times 10^{6}$ EAC cells freshly drawn from a donor mouse after collection from peritoneal cavity, purification and counting of viable cells by Trypan Blue.

The cell viability test was assessed using the trypan blue cell death assay (Strober, 2015). Briefly, portions of EAC cells $\left(1 \times 10^{4}\right)$ were incubated with different concentrations $(0-50 \mu \mathrm{g} / \mathrm{ml})$ of $\mathrm{rGO} / \mathrm{AgNC}$ at $37^{\circ} \mathrm{C}$ for $1 \mathrm{~h}$. After this incubation period, each mixture was carefully mixed with $0.4 \%$ trypan blue in $1: 1$ ratio and incubated for $2 \mathrm{~min}$. The stained mixtures were transferred to a hemocytometer to manually cell count. The percentage of cells admitting trypan blue dye to the total number of cells was determined by counting four different fields for each experimental condition. The assay was performed in triplicates.

\section{Animal experiments}

Female mice weighing 26-31 g were used in this study. They were housed with food and water ad libitum under standard environmental conditions of temperature and relative humidity a light/dark cycle of 12/12 h. Animal experiments have been approved by the university. They comply with the ARRIVE guidelines and were carried out in accordance with the U.K. Animals (Scientific Procedures) Act, 1986 and associated guidelines, and EU Directive 2010/63/EU for animal experiments.

For studying the in vivo effect of the prepared nanocomposite, mice were intraperitoneally injected with a dose of $10 \mathrm{mg} / \mathrm{kg} \mathrm{rGO/AgNC} \mathrm{for} 7$ days (Rahmanian et al., 2017). After this injection period, liver and kidney functions from the non-treated and treated groups were assessed, livers and kidneys were processed for histopathological and ultrastructural examinations, and estimation of silver content by the atomic absorption (Elsharawy et al., 2020).

For the assessment of the anticancer effect of $\mathrm{rGO} / \mathrm{AgNC}$, mice were randomly assigned to 3 groups: negative control; EAC ascites group, in which mice were inoculated with $4 \times 10^{6} \mathrm{EAC}$ cells; and EAC-rGO/AgNC, in which mice were inoculated with $4 \times 10^{6} \mathrm{EAC}$ cells, left for 1 week and then injected intraperitoneally with a dose of $10 \mathrm{mg} / \mathrm{kg}$ of $\mathrm{rGO} / \mathrm{AgNC}$ daily for 7 days. Mice survival, morphological and physiological characteristics, and exudate EAC cellular content were followed.

\section{Chemical analyses}

The mice liver and kidney samples were digested using a mixture of nitric acid ( $1 \mathrm{M})$ and perchloric acid $(1 \mathrm{M})$ at a ratio of $2: 1$ ( $\mathrm{v} / \mathrm{v})$ for $4 \mathrm{~h}$ and then incubated at $120^{\circ} \mathrm{C}$ until the vaporization of the remaining acids. Samples were diluted using known volume of distilled water and then filtered for silver (Ag) total mass measurement using the atomic spectrometer (PerkinElmer, PinAAcle-500, UK).

Sera were harvested from blood samples collected from different groups and stored at $-20^{\circ} \mathrm{C}$ until the determination of alanine transaminase (ALT), aspartate transaminase (AST), albumin, and creatinine as described before (Eldeeb et al., 2018).

\section{Statistical analysis}

Data were statistically analyzed using SPSS software version 25 . Values were expressed as the mean \pm standard deviation (SEM) and were analyzed with oneway Analysis of Variance (ANOVA), followed by t-test as a post hoc test. A $p<0.05$ was considered significant in all cases.

\section{Results}

\section{Characterization of the nanocomposite}

The first indication for the formation of rGO/AgNC was the color change from black into brown. rGO/AgNC was characterized by UV-vis spectrum, FT-IR, XRD and TEM analyses. The UV-vis spectrum (Fig. 1A) of GO confirmed the $\pi-\pi$ transitions of aromatic C-C bonds showing a peak at $230 \mathrm{~nm}$ (Gurunathan et al., 2015). The characteristic absorption peak for AgNPs appeared at $431 \mathrm{~nm}$ after their deposition on the surface of rGO. This band is assigned to the surface plasmons of AgNPs (Jebaranjitham et al., 2019).

FT-IR spectra (Fig. 1B) confirmed the characteristic peaks for GO that were observed at 3440 ( $\mathrm{OH}$ stretching), $1728(\mathrm{C}=0$ stretching), 1623 ( $\mathrm{C}=\mathrm{C}$ stretching) and $1041 \mathrm{~cm}^{-1}$ (C-O stretching). The presence of oxygen-containing functional groups such as hydroxyl, carboxyl and epoxy proved the successfully oxidation process of graphite powder to $\mathrm{GO}$ (Mukheem et al., 2018). Besides, after addition and reduction of silver ions $\left(\mathrm{Ag}^{+}\right)$, the $-\mathrm{OH}$ groups were stretched and shifted from 3404 to $3438 \mathrm{~cm}^{-1}$ that confirm the interactions between $\mathrm{Ag}^{+}$and/or AgNPs and the oxygenated groups on the rGO. The identified band $1625 \mathrm{~cm}^{-1}$ corresponded to the functional groups $(\mathrm{C}=\mathrm{C})$ that staying on $\mathrm{GO}$ plates indicating to the lack of amid progressions during the oxidation processes (Yuan \& Gurunathan, 2017).

Figure $1 \mathrm{C}$ and $1 \mathrm{D}$ showed the XRD of GO and $\mathrm{rGO} / \mathrm{AgNC}$. The XRD patterns for GO exhibited the (001) characteristic peak at $2 \theta=11.9^{\circ}$, which confirmed the closeness of oxygen-containing functional groups in negated spaces between graphene oxide sheets. However, this peak disappeared and a new peak at $2 \theta=$ 
$25.9^{\circ}$ was emerged indicating to the reduction of $\mathrm{GO}$ and the distance between its layers (Zhang et al., 2011). In addition, ten characteristic peaks of AgNPs appeared at $27.3^{\circ}, 31.7^{\circ}, 37.6^{\circ}, 43.9^{\circ}, 45.7^{\circ}, 54.3^{\circ}, 57^{\circ}, 64.26^{\circ}, 76.3^{\circ}$ and $77.4^{\circ}$, corresponding to respective crystal planes (100), (110), (111), (200), (200), (211), (211), (220), (311), and (311) (Galvez et al., 2021). The Ag diffraction peaks confirmed the incidence of the face centered cubic (FCC) crystal structure on the crystalline AgNPs (Hu et al., 2013). These results confirmed the synthesis of AgNPs after reduction and then loaded on the rGO surface (Li \& Liu, 2010).

The morphologies of the GO, rGO/AgNC and AgNPs samples were investigated directly by TEM. The TEM images showed the transparent and sheet-like structure of GO (Fig. 1E) and rGO/AgNC (Fig. 1F). Also, the spherical shaped and well-dispersed AgNPs were observed in the TEM and showed a mean size of 8-17 nm (Fig. 1F).

\section{Detection of rGO/AgNC in mice organs}

Mice were treated with $\mathrm{rGO} / \mathrm{AgNC}$ at a daily low dose of $10 \mathrm{mg} / \mathrm{kg}$ for a week. Results of this treatment have been summarized in Figs. 2 and 3 . Silver content has been estimated in both liver and kidney (Fig. 2A and 3D). The results showed a significant increase in silver content, indicating a highly nanocomposite uptake, especially in the kidney. For confirmation, both organs have been also processed for transmission electron microscopy (Fig. 2B, 2C, 3A-C), which showed deposits of nanoparticles in both organs.

\section{Effect of rGO/AgNC on mice}

\section{Effect of rGO/AgNC on the ultrastructure of the liver and kidney}

Transmission electron micrograph examination of control mice hepatocytes (Fig. 2B) revealed normal ultrastructural architecture of the hepatocytes. The nucleus had a double membrane of the nuclear envelops with nuclear pores. Heterochromatin dominated the peripheral nuclear areas and interchromatin granule clusters. The nucleolus was composed of dense fibrillar component, granular component and a fibrillar center, and accompanied by masses of heterochromatins. Golgi apparatus, mitochondria with cristae, outer and inner membranes, smooth endoplasmic reticulum, rough endoplasmic reticulum with ribosomes, lysosome, microbodies, and glycogen granules appeared normal.

Transmission electron micrograph examination of hepatocytes of mice treated with rGO/AgNC (Fig. 2C) revealed ultrastructural lesion in hepatocytes, which showed nucleus with disrupted organization of nuclear components as clumped heterochromatin and wrinkled nuclear membrane. The prominent feature lesion showed in cytoplasm was the electron lucent vacuolation adjacent to NP-containing endosomes. The mitochondrial abnormality was represented by rarely observed cristae and increased matrical substance. The observed few tiles of rough endoplasmic reticulum devoid ribosomes. Many ribosomes were recognized in cytoplasm.

Examination of transmission electron micrograph of control mouse renal tissue (Fig. 3A) revealed normal ultrastructural architecture of the proximal convoluted cuboidal epithelial cells. The large heterochromatic nucleus is located more toward the base than the apex of cell; many vacuoles distributed throughout the apical area of the cell; lysosomes, Golgi apparatus and apical microvilli and small endocytotic vesicles that have pinched off from the plasma membrane at the base of the microvilli showed normal appearance. The prominent feature observed in the cell of proximal convoluted epithelium is the extensive numbers of longitudinally oriented mitochondria presented in the cell within long invaginating folds of cell membrane, which caused basal striations appearance. The extreme basal aspect of these invaginating folds revealed a dense material that represents bundles of actin filaments. The electron micrograph also revealed thin basement membranes of the tubule, basal lamina and a small amount of connective tissue and the fenestrated endothelium of an adjacent peritubular capillary.

Examination of transmission electron micrograph of renal tissue from mice treated with rGO/AgNC (Fig. 3B and 3C) revealed ultrastructural lesions in the cuboidal cells of the proximal convoluted epithelium, which had shrinked nuclei with clumped heterochromatin. The mitochondrial aberration represented by rarely observed cristae, and the basal striations appearance are disorganized. The epithelial cells had thickened basement membranes of the tubule. The important lesion feature observed in the micrograph is represented by dense deposits of NPs distributed in many places and causing cytoplasmic distortion (Fig. 3C).

\section{Histopathological effect of $\mathrm{rGO} / \mathrm{AgNC}$ on the liver and kidney tissues}

Histological examination of liver from the control mice (Fig. 2F) revealed normal hepatic architecture. The hepatic parenchyma consisted of hepatocytes arranged in cellular plates radiating from the central vein at the center of hepatic lobules and several sets of blood vessels at its periphery. The peripheral vessels are grouped in connective tissue of the portal tracts and include a branch of the portal vein, a branch of the hepatic artery, and a branch of the bile duct (the portal triad). Both blood vessels in this triad branched as sinusoids, which ran between plates of hepatocytes.

Histopathological examination of liver revealed lesion associated with the treatment of rGO/AgNC (Fig. 2G). This lesion is characterized by disorganization of hepatic lobular structure, foci aggregation of inflammatory cells in the hepatic parenchyma surrounded by shrunken deeply acidophilic hepatocytes, periportal mild inflammatory cellular infiltration, degenerated and necrotic hepatocytes and some inflammatory cellular infiltration surrounded the central vein.

Renal histological section examination of control (Fig. 3F) revealed normal renal architecture. The renal parenchyma consisted of network of closely packed, proximal and distal convoluted renal tubules lined by acidophilic cuboidal cells, sectioned randomly in different planes. Spherical renal corpuscles are interspersed between renal tubules, each corpuscle contained glomerular capillary tuft that is surrounded by visceral and parietal epithelial layers of Bowman's capsule.

Examination of renal histological section from mice treated with rGO/AgNC (Fig. 3G) revealed degeneration and necrosis in cellular epithelia of proximal and distal renal convoluted tubules. The renal corpuscles appeared diminished and distorted with dilated Bowman space and bilobed or shrunk glomerulus. 


\section{Liver and kidney function}

The mice liver and kidney functions were tested by measuring ALT (Fig. 2D), AST (Fig. 2E), and creatinine (Fig. 3E) after treatment with rGO/AgNCs. The results revealed that the nano treatment significantly increased both hepatic enzymes ALT and AST as well as creatinine, indicating a damaging effect of $\mathrm{rGO} / \mathrm{AgNCs}$ on both organs.

Taken together, ultrastructural, histopathological, and biochemical examinations confirm that the green synthesized reduced graphene oxide / silver nanocomposite exerts a toxic effect in mice.

\section{Anticancer activity of the rGO/AgNC In vitro cytotoxic effect of rGO/AgNC}

For this purpose, EAC cells were grown in mice for a week and then isolated from their peritoneal exudates. These cells were incubated with different concentration of rGO/AgNCs as shown in Fig. 4 for an hour and then processed for vital staining via trypan blue exclusion. The results showed that all used $\mathrm{rGO} / \mathrm{AgNC}$ concentrations significantly reduced the viability of EAC cells in a concentration gradient manner, so that $50 \mu \mathrm{g} / \mathrm{mL}$ of $\mathrm{rGO} / \mathrm{AgNC}$ could be able to kill about $87 \%$ in $1 \mathrm{~h}$ (Fig. 4).

\section{Antitumor effect of $\mathrm{rGO} / \mathrm{AgNC}$ in vivo}

EAC cells were i.p. transplanted into mice and left to grow for a week before the daily i.p. injection of $10 \mathrm{mg} / \mathrm{kg} \mathrm{rGO/AgNC} \mathrm{for} \mathrm{another} \mathrm{week.} \mathrm{The} \mathrm{results}$ summarized in Fig. 5 reflected a clear regression of the ascites carcinoma and restoration of mice morphology and physiology. EAC cells from the peritoneal cavity were stained and counted every second day and showed daily reduction in their count after rGO/AgNC treatment (Fig. 5A). The nanocomposite-caused reduction in tumor cells restored the abdominal volume, circumference, and body weight in EAC bearing mice. The drop of the ascites volume restored the blood albumin level (Fig. $5 \mathrm{G}$ ). As a result of this $\mathrm{rGO} / \mathrm{AgNC}$ anticancer activity, no mortality was recorded in EAC bearing mice for the following 60 days $(\mathrm{n}=$ 9).

\section{Conclusions}

The present study demonstrated a green, economic, simple one-step biosynthesis method for rGO/Ag nanocomposite production using the crude metabolite of Escherichia coli D8 (MF06257) and sunlight. The formed rGO/AgNC sheets were decorated with well dispersed spherical shaped AgNPs. Although these $\mathrm{rGO} / \mathrm{AgNC}$ showed moderate toxicity in mice, they revealed a strong antitumor effect.

\section{Discussion}

During the last decades, rGO and AgNPs deserved an enormous academic interest and a significant attention especially as apoptotic agents (Zhang et al., 2011; Zhang et al., 2020; ). rGO is a compatible material to stabilize and disperse AgNPs since it is distinguished with the abundant oxygenated functional groups and large specific surface area (Ali et al., 2020). There were different methods that used reducing chemical agents in the synthesis of rGO/AgNC such as poly(N-vinyl-2-pyrrolidone) (Hu et al., 2013) and ammonia (Chook et al., 2012). Bao et al. (2011) prepared the rGO/ $\mathrm{AgNC}$ using $\mathrm{AgNO}_{3}$ as a salt precursor, hydroquinone as the reductant, and citrate as the stabilizer. Pasricha et al. (2009) synthesized the rGO/AgNC under alkaline conditions using sodium borohydride as a reducing agent to $\mathrm{Ag}^{+}$. In addition, different physical methods were used in synthesis the rGO/AgNC such as Zainy et al. (2012) who studied the preparation of $\mathrm{rGO} / \mathrm{AgNC}$ via rapid thermal treatment. They used silver acetate as a silver precursor and GO served as a substrate for the AgNPs that treated at $1000^{\circ} \mathrm{C}$ in a furnace for $20 \mathrm{~s}$ under an ambient atmosphere. On the other hand, the green synthesis approach of nanomaterials possesses minimum toxicity, lower-cost, lower reaction temperature and lower reaction time compared to the other physical and chemical methods (Awwad et al., 2020). Gurunathan et al. (2015) reported the synthesis of rGO/AgNC in three separated steps starting with synthesis of AgNPs using Tilia amurensis leaves extract, reduction of $\mathrm{GO}$ by $\mathrm{T}$. amurensis leaves extract and then mixing the $\mathrm{rGO}$ with $\mathrm{AgNO}_{3}$ to synthesized $\mathrm{rGO} / \mathrm{AgNC}$. Thus, the exploitation of green synthesized silver nanomaterials had an increasing interest in the elaboration of safe bioactive biomaterials in addition to their distinguished properties, such as antimicrobial activity, antiviral and antiangiogenesis action (Patil et al., 2019; Galvez et al., 2021). The present work provided a one-step green method for the synthesis of $\mathrm{rGO} / \mathrm{AgNC}$ by dual bioreducing of $\mathrm{GO}$ and $\mathrm{Ag}$ in the presence of sunlight and revealed promising effect of this nanocomposite in of cancer treatment. In addition, it explored the in vivo toxicity of this nanocomposite, and revealed a moderate effect on mice liver and kidney.

The main parameters of rGO/AgNC are its purity, shape and size which control its biological activities (Nel et al., 2006). The obtained data by UV-Vis spectroscopy, FT-IR, XRD and TEM studies confirmed the crystalline nature of AgNPs and strong interactions between the AgNPs and rGO. The TEM micrographs showed the transparent and sheet-like structure of $\mathrm{rGO} / \mathrm{AgNC}$ embedded with spherical shaped and well-dispersed AgNPs. These observations matched with that of Cobos et al. (2020) study in which the obtained $\mathrm{GO} / \mathrm{AgNC}$ sheets via the in situ method through the simultaneous reduction of $\mathrm{AgNO}_{3}$ and $\mathrm{GO}$ using L-ascorbic acid showed flexible sheets, paper-like structures morphologies of GO with few layers. The dark areas showed the thick stacking nanostructure of several GO and rGO/AgNC layers. The lower opaque areas designate much thinner sheets of a GO and rGO/AgNC layers indicating to their delamination. This exfoliation might increase the surface area of the synthesized materials (Stobinski et al., 2014). The resulting rGO/AgNC in the presented study showed the decorated AgNPs had an average size of 8-17 nm on the rGO sheets. Chook et al. (2012) fabricated GO/AgNC using microwave irradiation with $40.7 \pm 7.5 \mathrm{~nm}$ of AgNPs on the GO sheets. Yun et al. (2013) prepared GO/AgNC with deposited AgNPs with an average size of 2 to $4 \mathrm{~nm}$. 
There are many hypotheses for mechanisms of $\mathrm{rGO} / \mathrm{AgNC}$ formation but the more likely is the AgNPs were bound to $\mathrm{GO}$ through the collaboration of the Ag ${ }^{+}$ with the oxygenized functional groups on the GO surface such as the hydroxyl, epoxy and carboxylic groups (Faria et al., 2012). El-Dein et al. (2021) confirmed the presence of proteins in the biosynthesis of AgNPs by E. coli D8 as stabilizing and capping agents for AgNPs. The protein capping agents around the AgNPs might interact with GO-oxygenated groups as de Faria et al. (2014) supposed that as a probable mechanism of the biosynthesis of GO/AgNC which may be similar to our involved mechanism for the synthesis of $\mathrm{rGO} / \mathrm{AgNC}$.

Ehrlich carcinoma has a closeness with human tumors and is considered the most sensitive type to chemotherapy. EAC cells are undifferentiated cancer that are primordially hyperdiploid and does not have tumor-specific transplantation antigen. In addition, they have rapid proliferation, short life span as well as high transplantable capability (Ozaslan et al., 2011). In the present study, rGO/AgNC reduced EAC cell count in vitro in a dose-dependent manner. The potential in vivo toxicity of nanomaterials is always considered as a great concern for using in the biomedicine applications. The formation of solid tumors and the ascites elevate weight and abdominal circumference in mice and decrease the survival time (Ninomiya et al., 2009). The treatment with some chemicals decreased the amount of ascitic fluid without notably inspiring the number of tumor cells (Sugiura, 1958). In this study, treating Ehrlich carcinoma bearing mice with rGO/AgNC at the dose of $10 \mathrm{mg} / \mathrm{kg}$ for 7 days could prolong the survival for more than 60 days, while the rGO/AgNC-untreated ones were all died within 3 weeks. In addition, treatment with $\mathrm{rGO} / \mathrm{AgNC}$ restored body weight, abdominal circumference due to the reduction of the carcinoma cell viability and consequently of the ascitic fluid volume.

The penetration and accumulation of AgNPs in the treated mice were confirmed using histological and TEM examinations of liver and kidney. One of the main functions of the liver is to remove hazard compounds from the blood and transform those to suitable chemical forms that can be excreted by the kidney. Therefore, liver and kidney are the most prominent targets of nanoparticles. However, the observation of AgNPs in both organs infers the release of silver nanoparticles from the rGO/Ag nanocomposite. rGO/AgNC is formed of two parts: the rGO scaffolds and the decorated AgNPs. Polycationic rGO scaffolds could interact with the cell membrane negatively charged components (Ruiz-Herrera et al., 2006). It was reported that this interaction leads to the transposition of the potassium ions on the cell surface and losing of ionic equilibrium, which prompts the further efflux of potassium ions from the cell. This efflux leads to the hyperpolarization of the plasma membrane. It was affirmed that the plasma membrane hyperpolarization resort to the cell to increase the uptake of cations to balance the membrane potential (Peña et al., 2013). Vazquez-Muñoz et al. (2014) confirmed the gradual release and the spontaneous ionization of the $\mathrm{Ag}^{+}$from AgNPs. These ions penetrate the cell throughout a cationic influx. After $\mathrm{Ag}^{+}$entering the cells, different Ag related toxic effects may result as observed in this work. This observed toxic effects of AgNPs are in agreement with that of many previous reports (Hajipour et al., 2020; Elsharawy et al. 2020).

\section{Abbreviations}

rGO/AgNC: Reduced graphene oxide/silver nanocomposites

EAC: Ehrlich ascites carcinomaGO: Graphene oxide

rGO: Reduced graphene oxide

AgNPs: Silver nanoparticles

PNC: Polymer-based nanocomposites

UV-vis: Ultraviolet-visible

FT-IR: Fourier transform infrared spectroscopy

XRD: The X-ray diffraction

i.p.: Intraperitoneal

ALT: Alanine transaminase

AST: Aspartate transaminase

ANOVA: one-way Analysis of Variance

Declarations

\section{Availability of data and materials}

The datasets used and/or analyzed during the current study are available from the corresponding author on reasonable request.

\section{Ethics declarations}

Stated in the Material and method section.

\section{Consent for publication}


Not applicable.

\section{Availability of data and materials}

The datasets used and/or analyzed during the current study are available from the corresponding author upon request.

\section{Competing interests}

The authors declare that they have no competing interests.

\section{Funding}

Not applicable.

\section{Authors' contributions}

MME and MIA provided the bacterial strain. MME conducted the experiments. MMA performed biochemical analysis. AH performed statistical analysis and presented data in figures and tables. $\mathrm{AH}, \mathrm{AKA}$ and $\mathrm{ZAB}$ wrote the draft of the manuscript. All authors read and approved the manuscript.

\section{References}

1. Ali, A. A., Madkour, M., Sagheer, F. Al, Zaki, M. I., \& Abdel Nazeer, A. (2020). Low-temperature catalytic CO oxidation over non-noble, efficient chromia in reduced graphene oxide and graphene oxide nanocomposites. Catalysts, 10(1), 105. https://doi.org/10.3390/catal10010105

2. Anand, A., Unnikrishnan, B., Wei, S.-C., Chou, C. P., Zhang, L.-Z., \& Huang, C.-C. (2019). Graphene oxide and carbon dots as broad-spectrum antimicrobial agents-a minireview. Nanoscale Horizons, 4(1), 117-137. https://doi.org/10.1039/C8NH00174J

3. Awwad, A. M., Salem, N. M., Aqarbeh, M. M., \& Abdulaziz, F. M. (2020). Green synthesis, characterization of silver sulfide nanoparticles and antibacterial activity evaluation. Chem. Int, 6(1), 42-48. https://doi.org/10.5281/zenodo.3243157

4. Bao, Q., Zhang, D., \& Qi, P. (2011). Synthesis and characterization of silver nanoparticle and graphene oxide nanosheet composites as a bactericidal agent for water disinfection. Journal of Colloid and Interface Science, 360(2), 463-470. https://doi.org/https://doi.org/10.1016/j.jcis.2011.05.009

5. Ceran, Ö. B., Şimşek, B., \& Şara, O. N. (2020). Preparation and characterization novel dioctyl terephthalate blended polyvinyl alcohol-composite films incorporated with the graphene oxide and silver nanoparticles. Polymer Testing, 82, 106315. https://doi.org/10.1016/j.polymertesting.2019.106315

6. Chook, S. W., Chia, C. H., Zakaria, S., Ayob, M. K., Chee, K. L., Huang, N. M., Neoh, H. M., Lim, H. N., Jamal, R., \& Rahman, R. (2012). Antibacterial performance of Ag nanoparticles and AgGO nanocomposites prepared via rapid microwave-assisted synthesis method. Nanoscale Research Letters, 7(1), 1-7. https://doi.org/10.1186/1556-276X-7-541

7. Cobos, M., De-La-Pinta, I., Quindós, G., Fernández, M. J., \& Fernández, M. D. (2020). Graphene oxide-silver nanoparticle nanohybrids: Synthesis, characterization, and antimicrobial properties. Nanomaterials, 10(2), 376. https://doi.org/10.3390/nano10020376

8. de Faria, A. F., Martinez, D. S. T., Meira, S. M. M., de Moraes, A. C. M., Brandelli, A., Souza Filho, A. G., \& Alves, O. L. (2014). Anti-adhesion and antibacterial activity of silver nanoparticles supported on graphene oxide sheets. Colloids and Surfaces B: Biointerfaces, 113, 115-124.

https://doi.org/10.1016/j.colsurfb.2013.08.006

9. Dhanavel, S., Revathy, T. A., Sivaranjani, T., Sivakumar, K., Palani, P., Narayanan, V., \& Stephen, A. (2020). 5-Fluorouracil and curcumin co-encapsulated chitosan/reduced graphene oxide nanocomposites against human colon cancer cell lines. Polymer Bulletin, 77(1), $213-233$.

https://doi.org/10.1007/s00289-019-02734-x

10. El-Dein, M. M. N., Baka, Z. A., Abou-Dobara, M. I., El-Sayed, A. K., \& El-Zahed, M. M. (2021). extracellular biosynthesis, optimization, characterization and antimicrobial potential of Escherichia coli D8 silver nanoparticles. Journal of microbiology, biotechnology and food sciences, $10(4), 648-656$. https://doi.org/10.15414/jmbfs.2021.10.4.648-656

11. El-Sonbaty, S. M. (2013). Fungus-mediated synthesis of silver nanoparticles and evaluation of antitumor activity. Cancer Nanotechnology, 4(4-5), 73-79. https://doi.org/10.1007/s12645-013-0038-3

12. Eldeeb, E., Fahmy, S., Elbakry, K., \& Hyder, A. (2018). A single dose of the antineoplastics hydroxyurea or cisplatin has praziquantel-like effects on Schistosoma mansoni worms and host mouse liver. Biomedicine \& Pharmacotherapy, 99, 570-575. https://doi.org/10.1016/j.biopha.2018.01.098

13. Elsharawy, K., Abou-Dobara, M., El-Gammal, H., \& Hyder, A. (2020). Chitosan coating does not prevent the effect of the transfer of green silver nanoparticles biosynthesized by Streptomyces malachitus into fetuses via the placenta. Reproductive Biology, 20(1), 97-105.

https://doi.org/10.1016/j.repbio.2020.01.004

14. Faria, A. F, Martinez, D. S. T., Moraes, A. C. M., Maia da Costa, M. E. H., Barros, E. B., Souza Filho, A. G., Paula, A. J., \& Alves, O. L. (2012). Unveiling the role of oxidation debris on the surface chemistry of graphene through the anchoring of Ag nanoparticles. Chemistry of Materials, 24(21), 4080-4087. https://doi.org/10.1021/cm301939s

15. Galvez, A. M., Ramos, K. M., Teja, A. J., \& Baculi, R. (2021). Bacterial exopolysaccharide-mediated synthesis of silver nanoparticles and their application on bacterial biofilms. Journal of Microbiology, Biotechnology and Food Sciences, 2021, 970-978. https://doi.org/10.15414/jmbfs.2019.8.4.970-978 
16. Gomathi, A. C., Rajarathinam, S. R. X., Sadiq, A. M., \& Rajeshkumar, S. (2020). Anticancer activity of silver nanoparticles synthesized using aqueous fruit shell extract of Tamarindus indica on MCF-7 human breast cancer cell line. Journal of Drug Delivery Science and Technology, $55,101376$.

https://doi.org/10.1016/j.jddst.2019.101376

17. Gurunathan, S., Han, J. W., Park, J. H., Kim, E., Choi, Y.-J., Kwon, D.-N., \& Kim, J.-H. (2015). Reduced graphene oxide-silver nanoparticle nanocomposite: a potential anticancer nanotherapy. International Journal of Nanomedicine, 10, 6257-6276. https://doi.org/10.2147/IJN.S92449

18. Hajipour, P., Bahrami, A., Eslami, A., \& Hosseini-Abari, A. (2020). Chemical bath synthesis of CuO-GO-Ag nanocomposites with enhanced antibacterial properties. Journal of Alloys and Compounds, 821, 153456. https://doi.org/10.1016/j.jallcom.2019.153456

19. Hu, C., Liu, Y., Qin, J., Nie, G., Lei, B., Xiao, Y., Zheng, M., \& Rong, J. (2013). Fabrication of reduced graphene oxide and sliver nanoparticle hybrids for Raman detection of absorbed folic acid: a potential cancer diagnostic probe. ACS Applied Materials \& Interfaces, 5(11), 4760-4768. https://doi.org/10.1021/am4000485

20. Hummers Jr, W. S., \& Offeman, R. E. (1958). Preparation of graphitic oxide. Journal of the American Chemical Society, 80(6), 1339. https://doi.org/10.1021/ja01539a017

21. Idumah, C. I., Hassan, A., \& Ihuoma, D. E. (2019). Recently emerging trends in polymer nanocomposites packaging materials. Polymer-Plastics Technology and Materials, 58(10), 1054-1109. https://doi.org/10.1080/03602559.2018.1542718

22. Jebaranjitham, J. N., Mageshwari, C., Saravanan, R., \& Mu, N. (2019). Fabrication of amine functionalized graphene oxide-AgNPs nanocomposite with improved dispersibility for reduction of 4-nitrophenol. Composites Part B: Engineering, 171, 302-309. https://doi.org/10.1016/j.compositesb.2019.05.018

23. Jose, P. P. A., Kala, M. S., Joseph, A. V., Kalarikkal, N., \& Thomas, S. (2020). Reduced graphene oxide/silver nanohybrid as a multifunctional material for antibacterial, anticancer, and SERS applications. Applied Physics A, 126(1), 1-16. https://doi.org/10.1007/s00339-019-3237-x

24. Li, J., \& Liu, C. (2010). Ag/graphene heterostructures: synthesis, characterization and optical properties. Wiley Online Library. https://doi.org/10.1002/ejic.200901048

25. Ma, R., Wang, Y., Qi, H., Shi, C., Wei, G., Xiao, L., Huang, Z., Liu, S., Yu, H., \& Teng, C. (2019). Nanocomposite sponges of sodium alginate/graphene oxide/polyvinyl alcohol as potential wound dressing: In vitro and in vivo evaluation. Composites Part B: Engineering, 167, $396-405$. https://doi.org/10.1016/j.compositesb.2019.03.006

26. Morimoto, N., Kubo, T., \& Nishina, Y. (2016). Tailoring the oxygen content of graphite and reduced graphene oxide for specific applications. Scientific Reports, 6(1), 1-8. https://doi.org/10.1038/srep21715

27. Mukheem, A., Muthoosamy, K., Manickam, S., Sudesh, K., Shahabuddin, S., Saidur, R., Akbar, N., \& Sridewi, N. (2018). Fabrication and characterization of an electrospun PHA/graphene silver nanocomposite scaffold for antibacterial applications. Materials, 11(9), 1673. https://doi.org/10.3390/ma11091673

28. Mukherjee, S., Chowdhury, D., Kotcherlakota, R., \& Patra, S. (2014). Potential theranostics application of bio-synthesized silver nanoparticles (4-in-1 system). Theranostics, 4(3), 316-335. https://doi.org/10.7150/thno.7819

29. Nasr, H. A., Nassar, O. M., El-Sayed, M. H., \& Kobisi, A. A. (2020). Characterization and antimicrobial activity of lemon peel mediated green synthesis of silver nanoparticles. International Journal of Biology and Chemistry, 12(2), 56-63. https://doi.org/10.26577/ijbch-2019-v2-7

30. Nel, A., Xia, T., Mädler, L., \& Li, N. (2006). Toxic potential of materials at the nanolevel. Science (New York, N. Y.), 311(5761), $622-627$. https://doi.org/10.1126/science.1114397

31. Ninomiya, S., Inomata, M., Tajima, M., Ali, A. T., Ueda, Y., Shiraishi, N., \& Kitano, S. (2009). Effect of Bevacizumab, a Humanized Monoclonal Antibody to Vascular Endothelial Growth Factor, on Peritoneal Metastasis of MNK-45P Human Gastric Cancer in Mice. Journal of Surgical Research, 154(2), $196-202$. https://doi.org/https://doi.org/10.1016/j.jss.2008.08.017

32. Ozaslan, M., Karagoz, I. D., Kilic, I. H., \& Guldur, M. E. (2011). Ehrlich ascites carcinoma. African Journal of Biotechnology, 10(13), 2375-2378. https://doi.org/10.4314/ajb.v10i13.

33. Pasricha, R., Gupta, S., \& Srivastava, A. K. (2009). A facile and novel synthesis of Ag-graphene-based nanocomposites. Small, 5(20), $2253-2259$. https://doi.org/10.1002/smll.200900726

34. Patil, M. P., Seo, Y. B., Lim, H. K., \& Kim, G.-D. (2019). Biofabrication of gold nanoparticles using Agrimonia pilosa extract and their antioxidant and cytotoxic activity. Green Chemistry Letters and Reviews, 12(3), 208-216. https://doi.org/10.1080/17518253.2019.1623927

35. Peña, A., Sánchez, N. S., \& Calahorra, M. (2013). Effects of chitosan on Candida albicans: conditions for its antifungal activity. BioMed Research International, 2013. https://doi.org/10.1155/2013/527549

36. Pooresmaeil, M., \& Namazi, H. (2019). Preparation and characterization of polyvinyl alcohol/ß-cyclodextrin/GO-Ag nanocomposite with improved antibacterial and strength properties. Polymers for Advanced Technologies, 30(2), 447-456. https://doi.org/10.1002/pat.4484

37. Rahmanian, N., Eskandani, M., Barar, J., \& Omidi, Y. (2017). Recent trends in targeted therapy of cancer using graphene oxide-modified multifunctional nanomedicines. Journal of Drug Targeting, 25(3), 202-215. https://doi.org/10.1080/1061186X.2016.1238475

38. Rasoulzadehzali, M., \& Namazi, H. (2018). Facile preparation of antibacterial chitosan/graphene oxide-Ag bio-nanocomposite hydrogel beads for controlled release of doxorubicin. International Journal of Biological Macromolecules, 116, 54-63. https://doi.org/10.1016/j.ijbiomac.2018.04.140

39. Ruiz-Herrera, J., Victoria Elorza, M., Valentín, E., \& Sentandreu, R. (2006). Molecular organization of the cell wall of Candida albicans and its relation to pathogenicity. FEMS Yeast Research, 6(1), 14-29. https://doi.org/10.1111/j.1567-1364.2005.00017.x

40. Sabayan, B., Goudarzian, N., Moslemin, M. H., \& Mohebat, R. (2020). Green Synthesis and High Efficacy Method for Reduced Graphene Oxide by Zataria Multiflora Extract. Journal of Environmental Treatment Techniques, 8(1), 488-496. https://www.researchgate.net/profile/Nooredin-

Goudarzian/publication/338980183_Green_Synthesis_and_High_Efficacy_Method_for_Reduced_Graphene_Oxide_by_Zataria_Multiflora_Extract/links/5e3 Synthesis-and-High-Efficacy-Method-for-Reduced-Graphene-Oxide-by-Zataria-Multiflora-Extract.pdf

Page $8 / 13$ 
41. Soica, C., Pinzaru, I., Trandafirescu, C., Andrica, F., Danciu, C., Mioc, M., Coricovac, D., Sitaru, C., \& Dehelean, C. (2018). Silver-, gold-, and iron-based metallic nanoparticles: Biomedical applications as theranostic agents for cancer. In Design of nanostructures for theranostics applications (pp. 161-242). Elsevier. https://doi.org/10.1016/B978-0-12-813669-0.00005-1

42. Stobinski, L., Lesiak, B., Malolepszy, A., Mazurkiewicz, M., Mierzwa, B., Zemek, J., Jiricek, P., \& Bieloshapka, I. (2014). Graphene oxide and reduced graphene oxide studied by the XRD, TEM and electron spectroscopy methods. Journal of Electron Spectroscopy and Related Phenomena, $195,145-154$. https://doi.org/https://doi.org/10.1016/j.elspec.2014.07.003

43. Strober, W. (2015). Trypan blue exclusion test of cell viability. Current Protocols in Immunology, 111(1), A3-B. https://doi.org/10.1002/0471142735.ima03bs21

44. Sugiura, K. (1958). relative sensetivity of the solid and ascites forms of sarcoma 180 and Ehrlich carcinoma to inhibitory compounds*. Annals of the New York Academy of Sciences, 76(3), 575-585. https://doi.org/10.1111/j.1749-6632.1958.tb54876.x

45. Vazquez-Muñoz, R., Avalos-Borja, M., \& Castro-Longoria, E. (2014). Ultrastructural analysis of Candida albicans when exposed to silver nanoparticles. PloS one, 9(10), e108876. https://doi.org/10.1371/journal.pone.0108876

46. Yuan, Y.-G., \& Gurunathan, S. (2017). Combination of graphene oxide-silver nanoparticle nanocomposites and cisplatin enhances apoptosis and autophagy in human cervical cancer cells. International Journal of Nanomedicine, 12, 6537. https://doi.org/10.2147/IJN.S125281

47. Yun, H., Kim, J. D., Choi, H. C., \& Lee, C. W. (2013). Antibacterial activity of CNT-Ag and GO-Ag nanocomposites against gram-negative and gram-positive bacteria. Bulletin of the Korean Chemical Society, 34(11), 3261-3264. http://dx.doi.org/10.5012/bkcs.2013.34.11.3261

48. Yusof, H. M., Mohamad, R., \& Zaidan, U. H. (2020). Sustainable microbial cell nanofactory for zinc oxide nanoparticles production by zinc-tolerant probiotic Lactobacillus plantarum strain TA4. Microbial Cell Factories, 19(1), 1-17. https://doi.org/10.1186/s12934-020-1279-6

49. Zaidi, S. A. (2019). Effective imprinting of an anticancer drug, 6-thioguanine, via mussel-inspired self-polymerization of dopamine over reduced graphene oxide. Analyst, 144(7), 2345-2352. https://doi.org/10.1039/C8AN02348D

50. Zainy, M., Huang, N. M., Vijay Kumar, S., Lim, H. N., Chia, C. H., \& Harrison, I. (2012). Simple and scalable preparation of reduced graphene oxide-silver nanocomposites via rapid thermal treatment. Materials Letters, 89, 180-183. https://doi.org/https://doi.org/10.1016/j.matlet.2012.08.101

51. Zhang, C., Feng, X., He, L., Zhang, Y., \& Shao, L. (2020). The interrupted effect of autophagic flux and lysosomal function induced by graphene oxide in p62-dependent apoptosis of F98 cells. Journal of Nanobiotechnology, 18(1), 1-17. https://doi.org/10.1186/s12951-020-00605-6

52. Zhang, Z., Xu, F., Yang, W., Guo, M., Wang, X., Zhang, B., \& Tang, J. (2011). A facile one-pot method to high-quality Ag-graphene composite nanosheets for efficient surface-enhanced Raman scattering. Chemical Communications, 47(22), 6440-6442. https://doi.org/10.1039/C1CC11125F

\section{Figures}



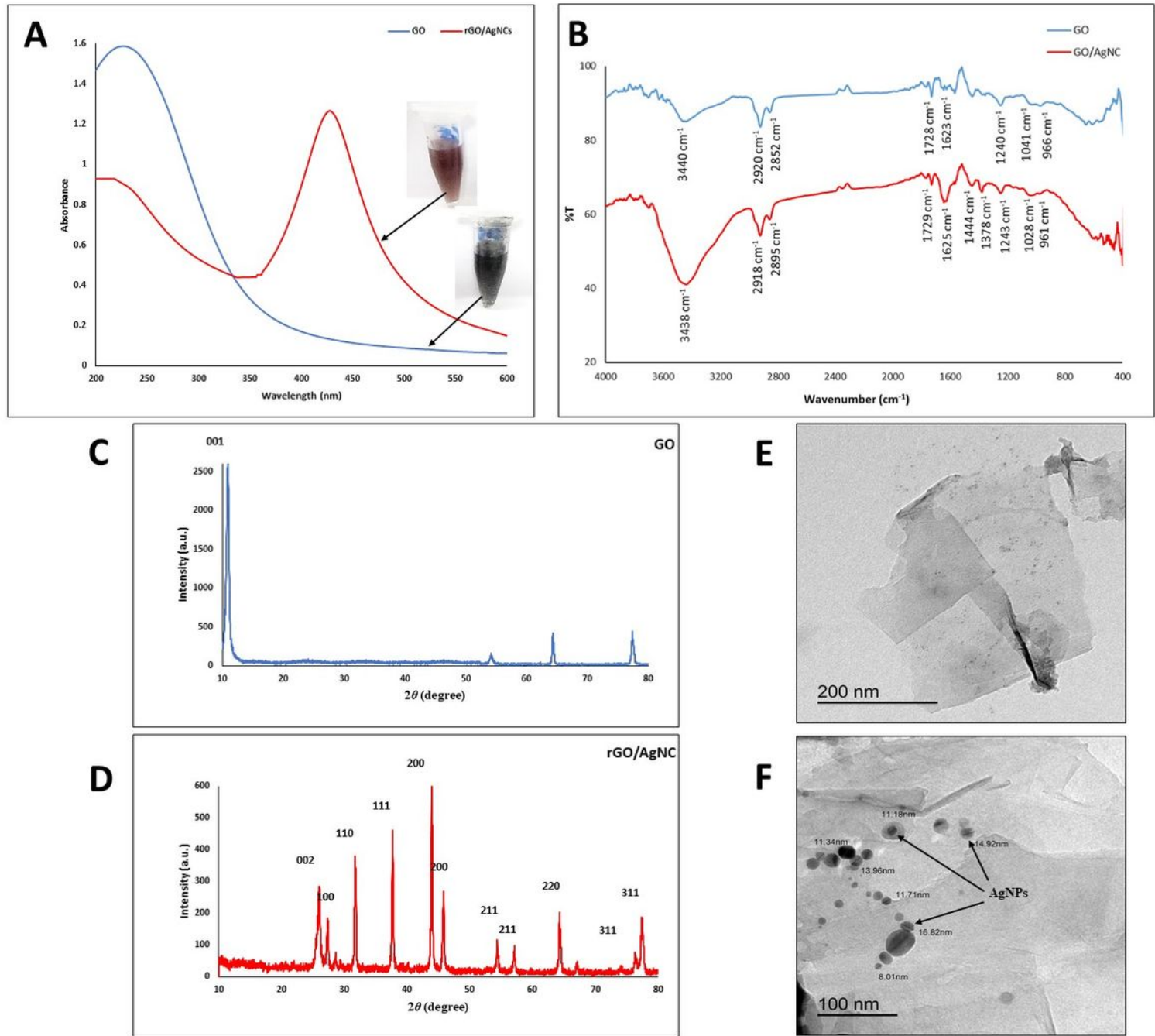

F

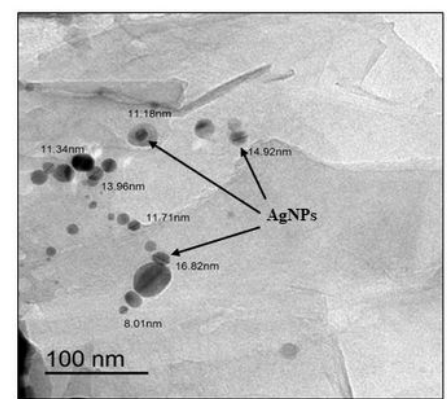

\section{Figure 1}

Characterization of reduced graphene oxide (GO) / silver nanocomposites (AgNC) biosynthesized by metabolite of E. coli: A) The UV-Vis spectra of GO and rGO/AgNC. B) FT-IR spectra of GO and rGO/AgNC. C) The X-ray diffraction (XRD) patterns of the GO and rGO. D) The X-ray diffraction (XRD) patterns of rGO/AgNC. E) Transmission electron microscopy (TEM) of GO. F) TEM of rGO/AgNC. 

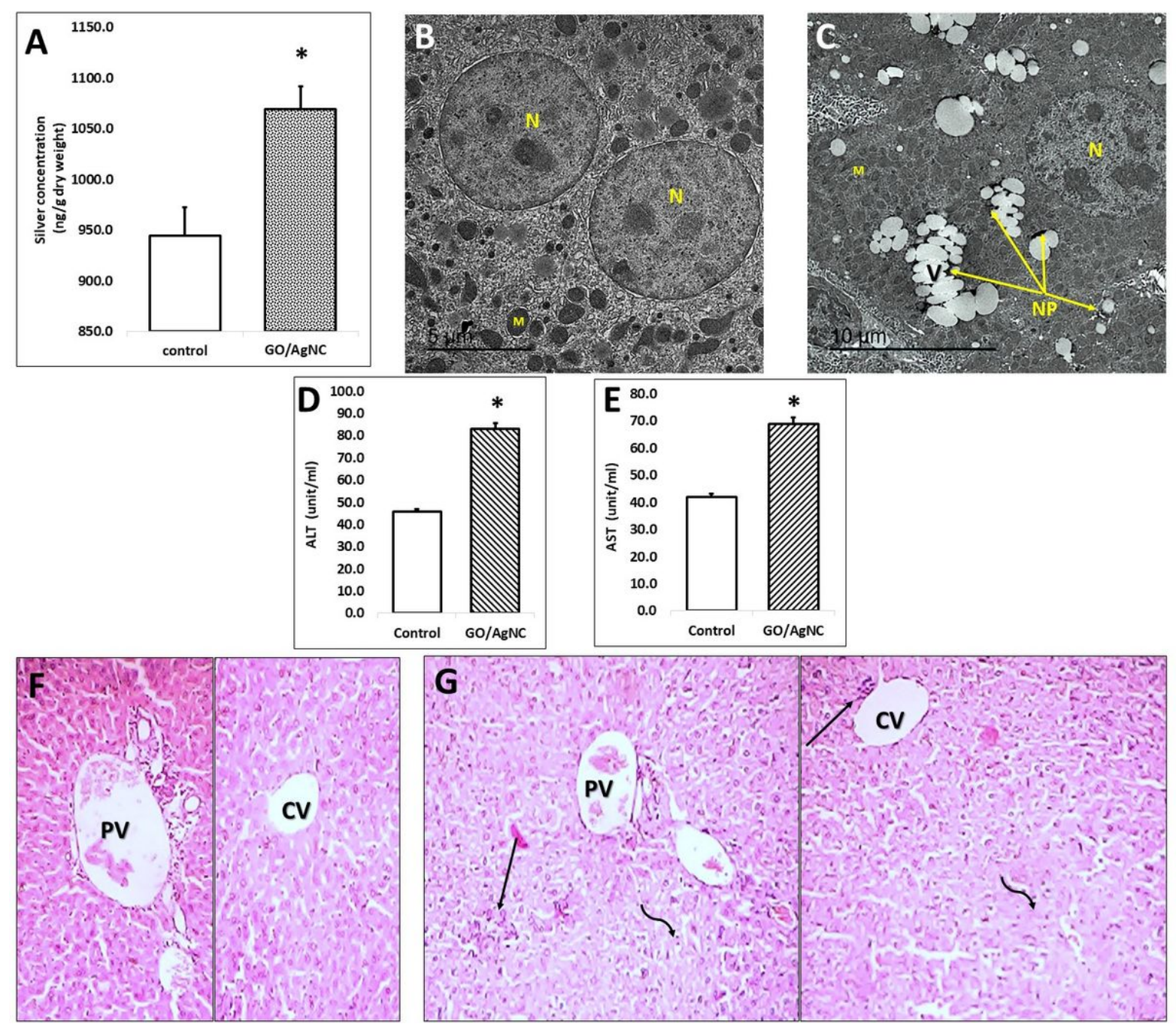

\section{Figure 2}

Effect of rGO/Ag nanocomposite biosynthesized by E. coli on mice liver. (A) silver content in the hepatic tissue. (B) TEM of control hepatocytes showing nuclei $(\mathrm{N})$ and mitochondria (M). (C) TEM of hepatocytes from mice treated with rGO/AgNC showing cytoplasmic vacuolation (V) associated with the presence of silver nanoparticles (NP). Liver function was assessed by assessing serum ALT (D), AST (E) and albumin (Fig. 5D). Histopathologic effect in livers of mice treated with $\mathrm{rGO} / \mathrm{AgNC}(\mathrm{G})$, compared to the control livers (F). abbreviations: PV, portal vein; CV, central vein; straight arrows show mild inflammatory leucocyte infiltration; curved arrows show areas of pycnotic nuclei and focal necrosis. * denotes statistically significant different value from the control one (t-test). 

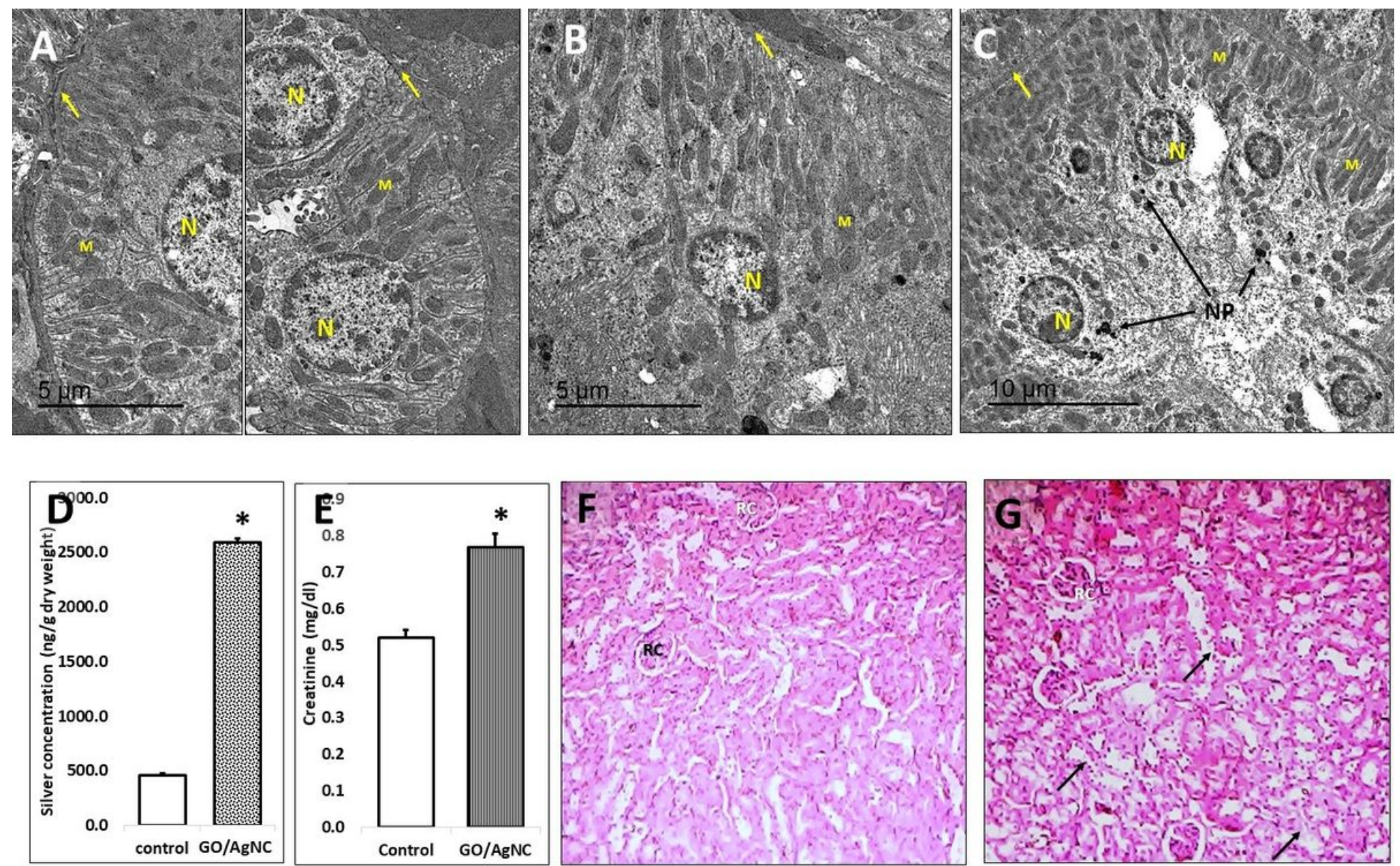

\section{Figure 3}

Reduced GO/Ag nanocomposites biosynthesized by E. coli are largely taken up by the kidney. TEM of convoluted tubules epithelia (A, control; B and C, nanocomposite-treated) showing shrinking nuclei $(\mathrm{N})$, mitochondrial aberration ( $\mathrm{M}$ ) and thickened basement membranes (arrows) in $\mathrm{B}$ and $\mathrm{C}$, compared to that in A. (D) silver content in the renal tissue. (E) Nanocomposite treatment increases serum creatinine. The * in D and E denotes statistically significant different value from the control one (unpaired t-test). Histopathologic effect in kidneys of mice treated with $\mathrm{rGO} / \mathrm{AgNC}(\mathrm{G})$, compared to the control ( $\mathrm{F}$ ), show dilated Bowman space of the renal corpuscles (RC) and degenerated and necrotic tubular epithelia (arrows).

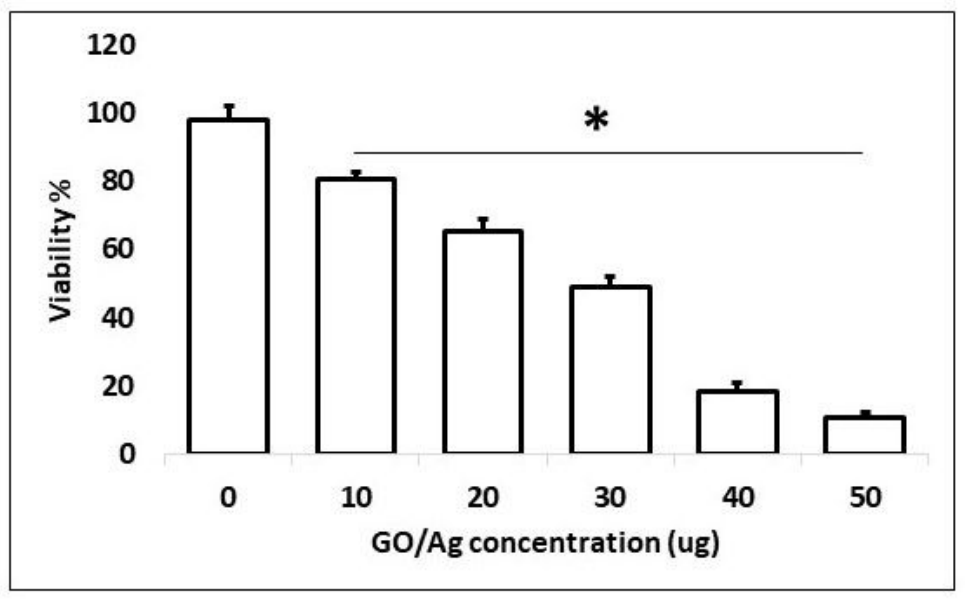

\section{Figure 4}

In vitro toxicity of $\mathrm{rGO} / \mathrm{AgNC}$ in Ehrlich ascites carcinoma cells. Cells were incubated with different concentrations of the nanocomposite for $1 \mathrm{~h}$ and viability was determined by trypan blue. * denotes significantly different values from the control one (ANOVA p<0.05). 

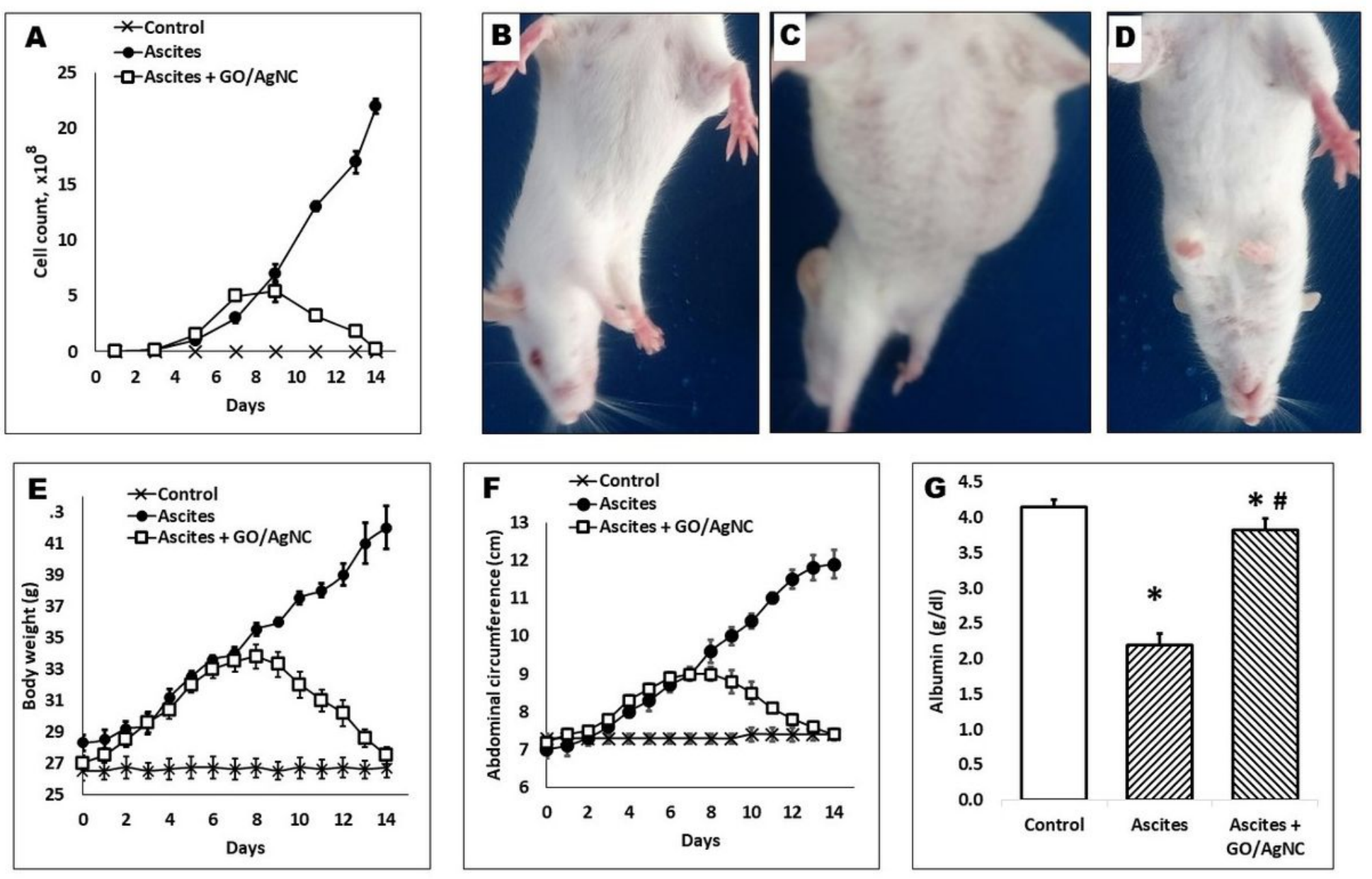

Figure 5

Antitumor effect of rGO/AgNC in vivo. (A) Daily reductions in Ehrlich ascites carcinoma (EAC) cells in the peritoneal exudate of mice treated with $10 \mathrm{mg} / \mathrm{kg}$ $\mathrm{rGO} / \mathrm{AgNC}$ for 7 days, a week after initial $4 \times 106$ EAC cell injection. (B-D) The nanocomposite reduces the ascites volume in EAC bearing mice: B) control mice, C) mice injected initially with EAC cells, and D) EAC-bearing mice treated daily with rGO/AgNC. (E and F) Restoration of the body weight and abdominal circumference in EAC-bearing mice after rGO/AgNC treatment. (G) Treatment with rGO/AgNC restores serum albumin level (ANOVA p<0.05, * and \# denote significantly different values, as determined by post-hoc t-test, from the control and EAC-bearing group, respectively).

\section{Supplementary Files}

This is a list of supplementary files associated with this preprint. Click to download.

- Graphicalabstract.jpg 